\title{
Diagnostic Study of Toxoplasmosis in Domestic Chickens in Sulaimani Province
}

\author{
A. A. Mohammed \\ Sh. H. Abdullah \\ Coll. of Vet. Med./ Unive. of Sulaimani
}

\begin{abstract}
Toxoplasma gondii causes toxoplasmosis in human and animals, a disease of cosmopolitan character. A total of 65 serum samples of domestic chickens (Gallus domesticus) from Sulaimani region were collected from May till August 2012.The overall seropositivity against $T$. gondii antibody was $60 \%$ based on the Latex agglutination test (LAT). The positive agglutination titers were ranged between 1:2 -1:128, and the highest seropositive rate observed at a titer 1:128 was $25.64 \%$. The present study demonstrated that anti Toxoplasma antibodies were high in chickens in this study.In histopathological examination of brain samples, tissue cysts were observed in 7 samples $33.33 \%$. About the Giemsa stained impression tissue smears of liver, kidney and spleen of all seropositive chickens tissue cysts also observed at the rate of $38.46 \%, 20.51 \%$ and $12.82 \%$ respectively, the results indicate that $T$. gondii localized in the liver more often than in other tissues of naturally infected chickens. This is the first report of $T$. gondii infection in domestic chickens in Sulaimani province.
\end{abstract}

\section{Introduction}

Toxoplasma gondii is an obligate intracellular protozoan that infects humans and a wide range of mammalians and birds (1). The ingestion of food or water contaminated with oocysts from cat feces or the ingestion of tissue cysts in undercooked meat are the two major ways of postnatal transmission of $T$. gondii (2).T. gondii has been recovered from a wide range of food animals including sheep, goats, pigs, rabbits, and domestic poultry (3).Naturally occurring infections with Toxoplasma have been sought in several species of wild birds, and pigeon. The first known demonstration of toxoplasmosis of the mammalian type in birds, in eastern North America. Experimental infections with a strain of Toxoplasma of human origin have been studied in pigeons, song sparrows, grackles, and chickens (4).Ground-feeding birds are considered important in the epidemiology of T.gondii because they serve as indicators of soil contamination by oocysts, cats excrete environmentally resistant oocysts after consuming tissues of $T$. gondiiinfected birds (5).Birds can be considered important reservoirs of $T$. gondii as they are often hunted by felids (6).One of the main sources of infecting humans, is bird meat, so besides another indicators to detect the distribution of $T$. gondii oocysts in the environment, the determination of T.gondii prevalence in domestic birds is of great importance (7). Routine diagnosis of $T$. gondii infection is commonly performed by serological tests for detection of specific antibodies $(8,9)$. However, a preliminary diagnosis can be made by examining Giemsa-stained impression smears of affected tissues (10).Human seropositivity was reported $58.06 \%$ in Sulaimani province about the animals in sheep and goats the prevalence rate was $56.91 \%$ (11), and in cat was $(18 \%)$ in the study area ( 12$)$. The study was done to investigate the prevalence of Toxoplasma gondii in village chicken (Gallus domesticus), which used as a food source in Sulaimani province, to assess the role of infected chickens in the epidemiology of toxoplasmosis in humans, by serologic and histopathologic methods of diagnosis. 


\section{Materials and Methods}

A total of 65 chickens (Gallus domesticus) of different ages were purchased from different sources in Sulaimani province for Toxoplasma gondii detection by serological, Histopathological, and impression smear examination, from May to August 2012.

\section{Methods}

Blood samples were collected from brachial vein, about $3 \mathrm{ml}$ from each chicken in clean test tubes, serum was isolated by centrifugation of blood samples at 3000 rpm for 5-10 minutes, and stored at $-20^{\circ} \mathrm{C}$ till using for antibodies detection.(13) Latex agglutination test, Latex Test kit (UK) was used for detection of Toxoplasma gondii antibodies in vitro. A qualitive test for all the samples while quantitave test for the

\section{Results}

Out of 65examined chickens 39 (60\%) were seropositive for Toxoplasma antibody by LAT, The positive agglutination titers were distributed between 1:2 -1:128, and the highest seropositive rate at a titer 1: 128 was $25.64 \%$, and the antibody titers were $1: 2$ in $2,1: 4$ in $4,1: 8$ in $6,1: 16$ in $5,, 1: 132$ in 4 , $1: 64$ in 8 and $1: 128$ in 10 chickens as shown in Table (1).Histological positive samples. (14).The chickens were bled and killed, brains were removed for Histological examination, 21 brain samples from serologically positive chickens were transferred to laboratory for detection the presence of tissue cyst, the first step was performed by fixing the organ in $10 \%$ neutral buffered formalin, sectioned at $4 \mu \mathrm{m}$ and stained with Haematoxylin and Eosin stain ,tissue sections were then examined microscopically under oil lens (14).Also visceral organs including liver, spleen and kidneys were removed and examined by preparing of Giemsa-stained impression smears from them for tachyzoites and tissue cyst detection microscopically under oil lens.

Table 1: Distribution of latex agglutination test antibodies to the T. gondii in domestic chickens.

\begin{tabular}{|c|c|c|c|c|c|c|c|c|c|}
\hline \multirow{2}{*}{$\begin{array}{l}\text { No. of } \\
\text { examined }\end{array}$} & \multirow{2}{*}{$\begin{array}{l}\text { No. of } \\
+ \text { ve }\end{array}$} & \multirow{2}{*}{$\begin{array}{l}\% \text { of } \\
+ \text { ve }\end{array}$} & \multicolumn{7}{|c|}{ Antibody titration } \\
\hline & & & $1: 2$ & $1: 4$ & $1: 8$ & $1: 16$ & $1: 32$ & $1: 64$ & $1: 128$ \\
\hline 65 & 39 & 60 & 2 & 4 & 6 & 5 & 4 & 8 & 10 \\
\hline
\end{tabular}




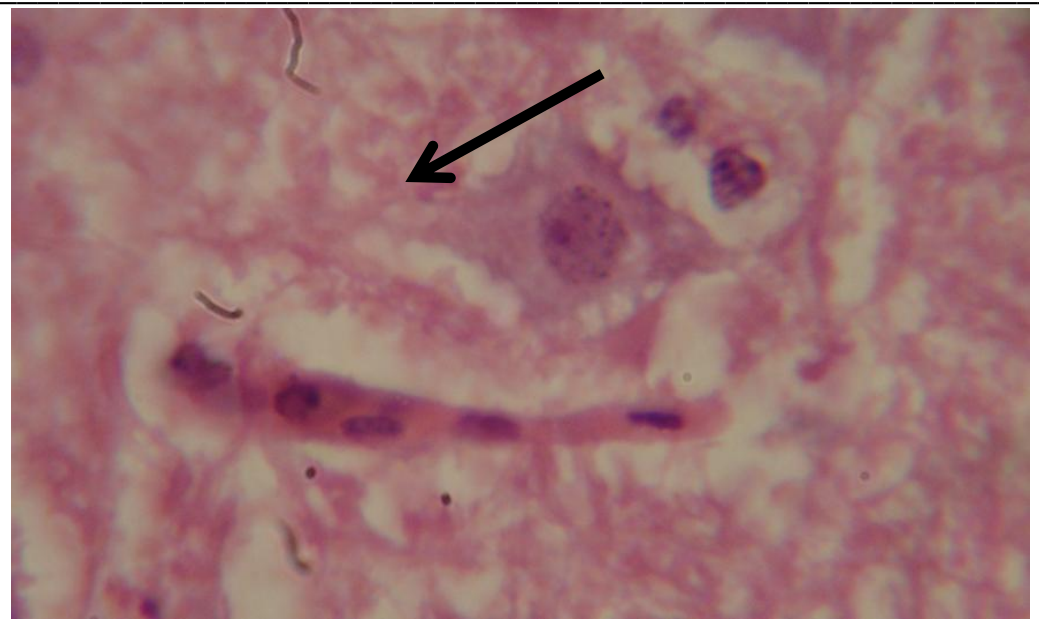

Figure (1) Tissue cyst of Toxoplasma gondii in brain of infected chicken, stained by Haematoxylin and Eosin. 100X (oil lens).

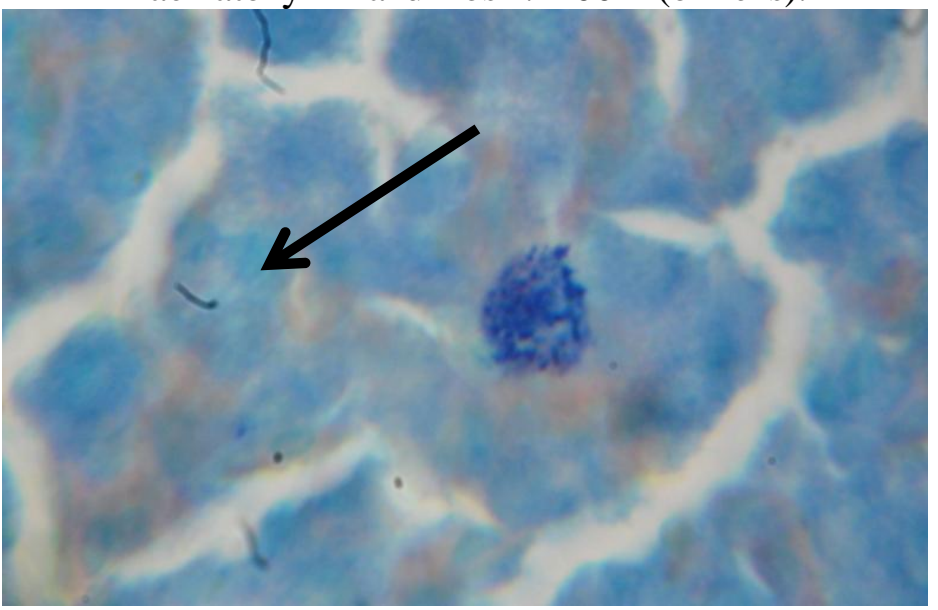

Figure (2) Tissue cyst of Toxoplasma gondii in liver of infected chicken stained by Geimsa stain. 100X (oil lens).
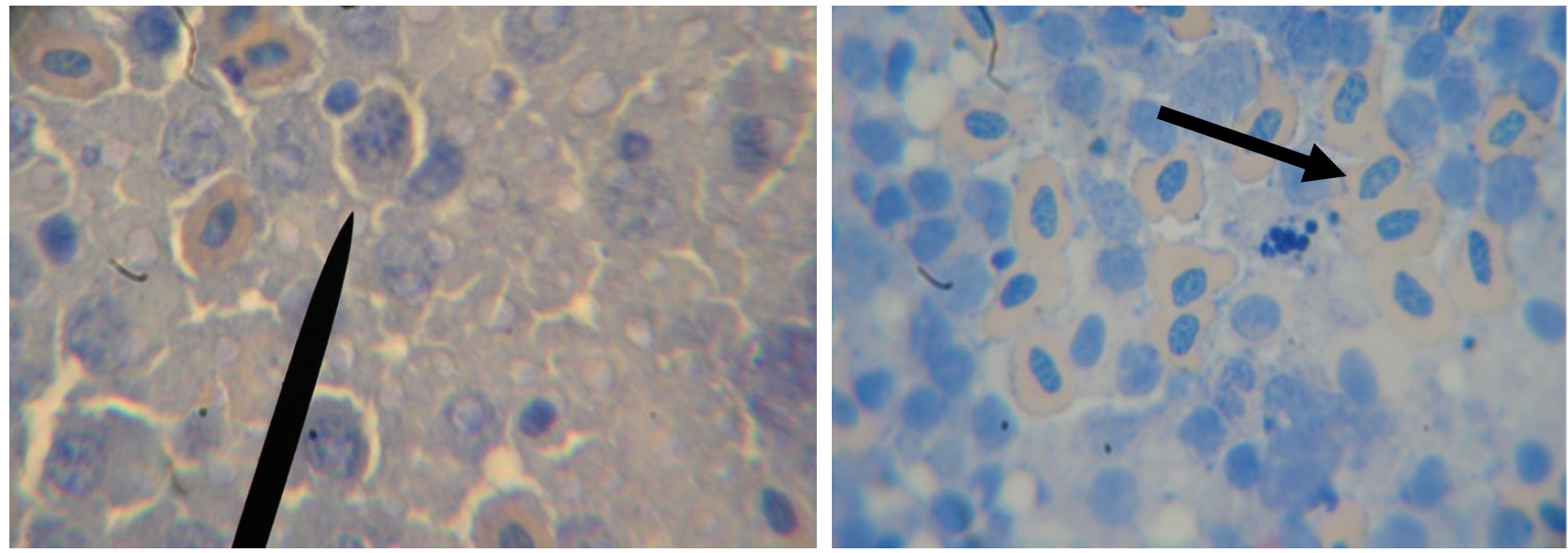

Figure ( $3 \& 4$ ) Tissue cyst of Toxoplasma gondii in kidney and spleen of infected chicken stained by Geimsa stain. 100X (oil lens). 


\section{Discussion}

Chickens are considered one of the most important hosts in the epidemiology of Toxoplasma gondii infection because they are an efficient source of infection for cats that excrete the environmentally resistant oocysts and because humans may become infected with this parasite after eating undercooked infected chicken meat (15).Diagnosis of toxoplasmosis has been conducted by histological examination, necropsy findings, immunohistochemical, bioassays and serological methods in avian species (16, 17). The study revealed a high seroprevalence of $60 \%$ in free-ranging chicken, that was close to result of (18) in Chile who found $55.39 \%$. Our data was higher than the result of obtained by (19) in Egypt, (3) in Iran and (20) in Colombia as they reported seroprevalence of $40 \%, 43 \%$ and $44.4 \%$, respectively in chickens. While (21) reported $81.81 \%$ in Ninevah governorate/ Iraq in Broiler chickens and in Brazil (22) reported a high seroprevalence rate of $84.92 \%$ which are higher than our results. The various prevalence of the disease may be associated with the geographical location and type of serological tests (2). The result of Antibody titration by LAT showed that, higher titer was 1:128 which is reported in $25.64 \%$ .The prevalence of T.gondii antibodies in chicken were reported from nil to $40 \%$ by different method using different cut of points (23).The present study demonstrated that anti Toxoplasma antibodies were high in chickens in the studied area. It seems that chickens become infected mostly during feeding on the ground contaminated with oocysts (3). Humidity and temperate temperature favor the oocyst survival (24). The susceptibility for $T$. gondii infection in birds could be demonstrated though susceptibility for clinical disease often seems to be low, especially in gallinaceous birds (25), and chickens are considered resistant to clinical toxoplasmosis. There are only a few reports of clinical toxoplasmosis in chickens worldwide (14).Hens from the experimental infection with 50,000 infective oocysts showed an egg-drop and mortality in embryonated eggs, especially during the first 2 weeks p. i. (post inoculation) (26). Chicken belong to the current study were clinically healthy. The development of a reliable serologic test (dye test) by Sabin and Feldman (1948) made it possible to serologically compare assumed $T$. gondii infection from various animal species. However, in most cases, the diagnosis will be made by histologic examination (10).In current study, tissue cysts of parasite was observed in histologically examined brains of 21 seropositive chickens in 7 of them $33.33 \%$, also (27) reported by histological examination that $T$. gondii was found in sections of brains of three out of nine examined. Also in Giemsa stained impression smear from the visceral organs liver, kidneys and spleen of seropositive chickens with 15 $(38.46 \%), 8(20.51 \%)$ and $5(12.82 \%)$ respectively, as the highest rate was observed in liver. Also (23) reported the highest rate of infection was seen in liver of the seropositive chickens (93.1\%) (27 out of 29) while the lowest was observed in hearts in 16 out of 29 chicken by using PCR method. The liver is usually consumed undercooked; therefore, bradyzoites of parasite stay alive and may cause Toxoplasma infection. The consumption of semi-raw liver especially in pregnant women and children is conventional.T. gondii tachyzoites in smears are crescentic to globular, depending on the stage of division .However, in histologic sections tachyzoites are globular to oval and about half of the size of those in smears (10).Because domestic birds could have a potential role in transmitting toxoplasmosis to humans (3) Control measure should be taken to prevent transmission of the infection to the animals and humans by health and veterinary organizations (12) . 


\section{References}

1-Smith, J. E, and Reduck, N. R. (2000). Toxoplasma gondii strain variation and pathogeniticity. In: Cary, J. W., Linz, Bhatnagar, B. CEDs, Microbial food borne diseases: Mechanisms of pathogenesis and toxin synthesis. Technnomic pubilishing, Lancaster, PA,; pp. 405-431.

2. Karatepe, M.; Kilıç, S.;Karatepe, B. andBabü, B. (2011).Prevalence of Toxoplasma gondii Antibodies in Domestic (Columba livia domestica) and Wild (Columba livia livia) Pigeons in Niğde region, Turkey. Turkiye Parazitol Derg. 35: 23-6.

3. Zia-Ali, N., Keshavarz-Valian, H., Rezaian, M., Khorramizadeh, M.R., Kazemi, B., Fazaeli, A , and Darde, M. (2005). Molecular Characterization of Toxoplasma gondii from Bird Hosts. Iranian $\mathrm{J}$ Publ Health, Vol. 34, No. 3, pp.2730.

4.Manwell, R. D. , Drobeck ,H. P. (2004).Mammalian toxoplasmosis in birds J. Experimental Parasitology. Volume 1, Issue 1, 83-93.

5. Dubey, J. P. ,Felix, T. A. and Kwok, O. C. H.(2010). Serological and Parasitological Prevalence of Toxoplasma gondii in Wild Birds From Colorado. Journal of Parasitology 96(5):937-939.

6. eGodoi, F. S. L., Nishi ,S. M. , Jesus Pena ,H. F. and Gennari S. M. (2010). Toxoplasma gondii: diagnosis of experimental and natural infection in pigeons (Columba livia) by serological, biological and molecular techniques. Rev. Bras. Parasitol.Vet.,Jaboticabal, v. 19, n. 4, p. 238-243, out.-dez.
7. Dubey JP, Graham DH, Dahl E, Hilali M, El-Ghaysh A, Sreekumar C, Kwok OC, Shen SK, Lehmann T (2003). Isolation and molecular characterization of $T$. gondii from chickens and ducks from Egypt. Vet Parasitol, 114: 89-95.

8. Dubey, J. P. et al.(2007). Biologic and genetic comparison of Toxoplasma gondii isolates in free-range chickens from the northern Pará state and the southern state Rio Grande do Sul, Brazil revealed highly diverse and distinct parasite populations. Veterinary Parasitology, v. 143 , n. 2, p. 182188 ,

9. Dubey, J. P. et al. (2005). Genetic and biologic characteristics of Toxoplasma gondii isolates in freerange chickens from Colombia, South America. Veterinary Parasitology, v. 134, n. 1-2, p. 6772 ,

10. Dubey, J.P. (2002) A review of toxoplasmosis in wild birds. Veterinary Parasitology.106 .121153.

11. Abdullah, S. H. (2008). Seroprevalence and Isolation of Toxoplasma gondii in Sulaimani Province. M.Sc. Thesis, College of Veterinary Medicine, University of Sulaimani , Iraq.

12. Muhammed, S. M. (2007). Serological Study of Toxoplasmosis in Definitive and Intermediate Hosts in Sulaimani City. M.Sc. Thesis, Department of Biology/ College of Science, University of Baghdad, Iraq.

13. Drury RAB, Wallington E A. Carleton's histological technique. 5th ed. Oxford University Press, Oxford. 1980.

14. Butty, E. T.(2009). Diagnostic study of Toxoplasma gondii in turkey 
(Meleagris gallopavo) in some regions in Ninevah governorate, Iraq . Iraqi Journal of Veterinary Sciences, Vol. 23, Supplement I, (57-62).

15. Dubey, J. P. (2010).Toxoplasma gondii Infections in Chickens (Gallus domesticus ): Prevalence, Clinical Disease, Diagnosis and Public Health Significance. The public domain in the USA 57.60-73.

16.Last, R. D. and Shivaprasad, H.L. (2008). An outbreak of toxoplasmosis in aviary collection of Nicobar pigeons (Caloenasni cobaria). J S Afr Vet Assoc; 79: 149-52.

17.Dubey, J.P.(2002) A review of toxoplasmosis in wild birds. Vet Parasitol 106: 121-53.

18.Dubey, J.P.;Patitucci, A. N.; Su, C., Sundar, N.; Kwok, O. .H. and Shen, S. $\quad$ K.(2006a) Characterization of Toxoplasma gondii isolates in free range chickens from Chile. Vet Parasitol; 140: 76-82.

19. Dubey, J.P.; Graham, D.H.; Dahl, E ;Hilali, M.; El Ghaysh, A.;Sreekumar, C.; Kwok, O. C.H. ; Shen, S. K. and Lehmann, T.(2003).Isolation and molecular characterization of Toxoplasma gondii from chickens and duck from Egypt. Vet Parasitol.; 114: 89-95.

20. Dubey, J.P.; Graham, D.H.; Dahl, E ;Hilali, M.; El Ghaysh, A.; Sreekumar, C.; Kwok, O. C.H. ; Shen,S.K.and Lehmann, T.(2006b). Genetic and biologic characteristics of Toxoplasma gondii isolates in free-range chickens from Colombia, South America. Vet Parasitol.; 141: 4247.
21. Mahmood, A. F.; Nashwan, A. A.; Waked, H. M.; Bashar, M .J. and Yaser, Y.H. (2006).Detection of Toxoplasma gondii antibodies in Broiler chickens in Ninevah governorate. Journal of Dohuk University; $\quad 9: 145-148$.

22. Leite, A.S., Alres, L. C. and Faustion, M.A.G.(2007) Serological survey of toxoplsmosis in birds from Cracidae family in a wild bird center facility at Pernambuco state, North East of Brazil. Medicina Veterina, Recife. Vol. 1, No.1 pp55-57.

23.Tonter, A.M., Heckeroth, A. R. and Weiss L. M. (2000).Toxoplasma gondii from animal to human. Int. J. Parasita.; 30: 1217-58.

24. Asgari, Q. ,Motazedian, M.H., Esmaeelzadeh, B., Kalantari, M. and Hatam, Gh. R.(2009). The Prevalence of Toxoplasma Infection among Free-Ranging Chickens in Southern Iran Using IFA and Nested-PCR Iranian J Parasitol: Vol. 4, No.4, pp.29-36 .

25. Bangoura, B., Zöller, B., and Daugschies, A.(2011). Prevalence and relevance of avian Toxoplasma gondii infections in Europefile.Berl Munch Tierarztl Wochenschr. Nov-Dec;124(1112):485-96.

26. Biancifiori, F., Rondini, C., Grelloni, V. and Frescura, T. (2000). Avian toxoplasmosis: experimental infection of chicken and pigeon. Comp Immunol Microbiol Infect Dis. 9(4):337-46.

27. Dubey, J. P. (2010).Toxoplasma gondii Infections in Chickens (Gallus domesticus ): Prevalence, Clinical Disease, Diagnosis and Public Health Significance. in public domain in the USA $5760-73$. 
$\begin{array}{llll}\text { AL-Qadisiya Journal of Vet.Med.Sci. } & \text { Vol./12 } & \text { No./2 }\end{array}$

دراسة تشخيصية لداء المقوسات في الاجاج المحلية في المحافظة السليمانية

$$
\text { أرام أحمد محمد البيطري/ جامعة السليمانية عبدلة }
$$

\section{الخلاصة}

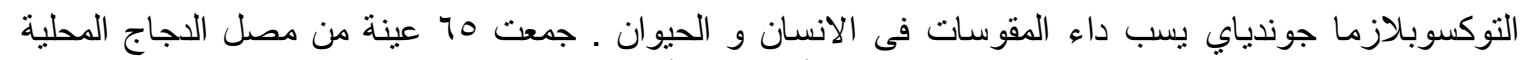
(Gallus domesticus)

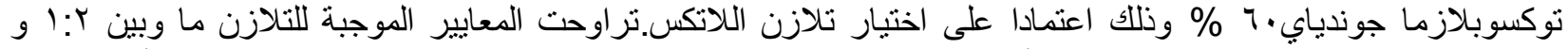

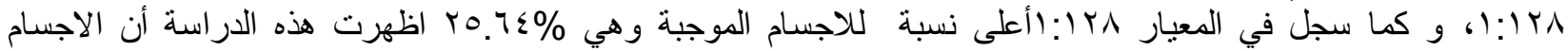

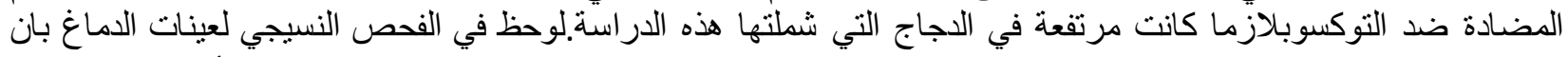

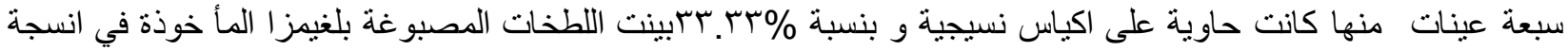

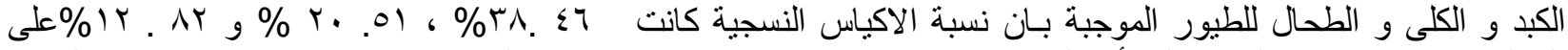

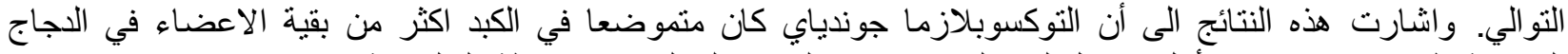
المصابة طبيعيا ـ ويعتبر هذا أول تسجيل لداء المقاء التوسات في الاجاج المحلي في محافظة السليمانية. 